\title{
Rapid diagnosis of infantile spinal muscular atrophy by direct amplification of amniocyte and CVS DNA
}

\author{
Alex MacKenzie, Anne Besner, Natalie Roy
}

Our laboratory, like those of Daniels et $a l^{1}$ and Melki et $a l,{ }^{2}$ is conducting prenatal diagnoses of type 1 spinal muscular atrophy (SMA) by means of linkage analysis with $5 \mathrm{q} 13$ polymorphisms. In our experience, a decision for pregnancy termination is taken if a diagnosis of SMA is made. Consequently, in the interests of generating a rapid prenatal SMA diagnosis, we have recently opted for a solely PCR based methodology using amniocyte or chorionic villus DNA as template.

A 1 year old infant girl who had been noted by her parents to be 'floppy and weak' from approximately 7 months was diagnosed as having type 1 SMA on the basis of EMG and muscle biopsy. ${ }^{3}$ The mother was 16 weeks pregnant at the time of diagnosis and consequently requested prenatal diagnosis. Amniocentesis was conducted the next day; $15 \mathrm{ml}$ of amniotic fluid were drawn for cell culturing and eventual DNA extraction and an additional $9 \mathrm{ml}$ were taken for direct $5 \mathrm{q} 13$ microsatellite CA repeat genotyping. Various approaches were used in the preparation of the amniotic fluid for PCR. The most effective was found to be a Chelex (Bio-Rad) based approach $^{4}: 100 \mu \mathrm{l}$ of amniotic fluid was mixed with an equal volume of $5 \%$ Chelex, heated at $56^{\circ} \mathrm{C}$ (30 minutes), vortexed, heated at $100^{\circ} \mathrm{C}$ (eight minutes), vortexed, and centrifuged (three minutes, $10000 \mathrm{~g}$ ). Optimal results were obtained using 5 to $10 \mu \mathrm{l}$ of this supernatant in $25 \mu \mathrm{l}$ PCR reaction volumes. Primer sequences and reaction conditions were as described ${ }^{15-7}$ except that a two minute extension time was used for MAPIB microsatellite repeats. Reaction products were run on an $8 \%$ polyacrylamide gel, the gel dried, and autoradiographs developed.

In a second case, a 9 month old infant boy was admitted to paediatric ICU in respiratory failure. A diagnosis of type 1 SMA was made after EMG and muscle biopsy. The infant died at 10 months. The parents conceived again and a chorionic villus sampling was performed at 11 weeks. Two CVS strands were placed in $100 \mu \mathrm{l}$ of $\mathrm{dH}_{2} \mathrm{O}$ and then added to an equal volume of $5 \%$ Chelex. Treatment thereafter was identical to that used for amniocyte DNA.

The physical disposition and approximate
Division of Genetics, Children's Hospital of Eastern Ontario, 401 Smyth, Ottawa,

Ontario, Canada K1H

8 L1.

A Mackenzie

A Besner

N Roy

Correspondence to Dr MacKenzie.

Received 19 June 1992. Revised version accepted 16 July 1992.

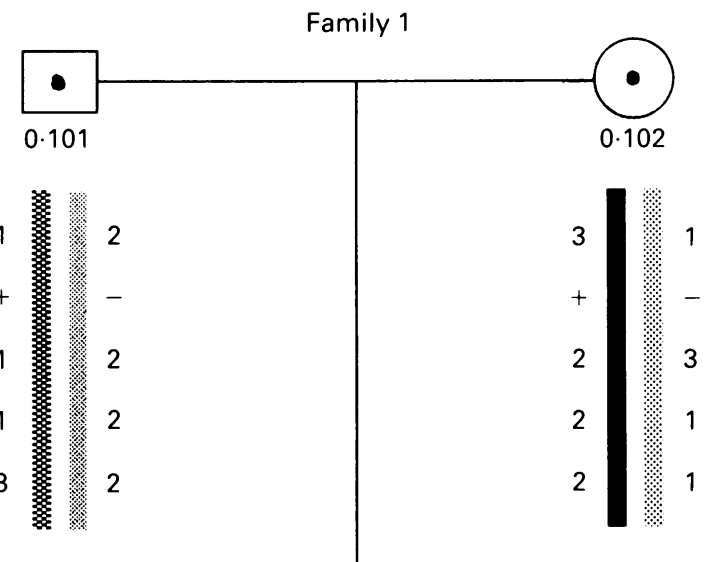

D5S76

SMA

MAPIB1

MAPIB2

D5S39

3

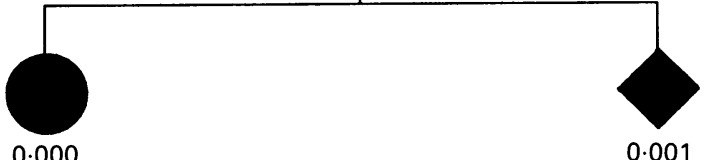

D5S76

SMA

MAPIB1

MAPIB2

D5S39

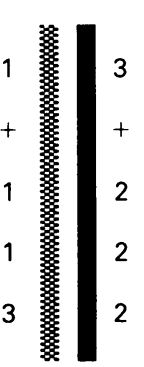

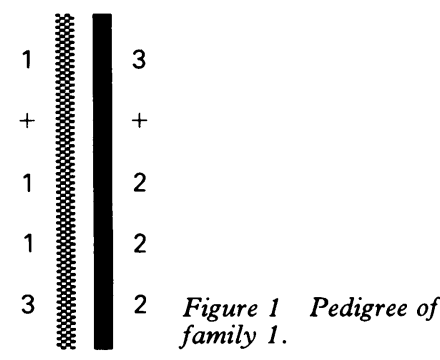


Family 2

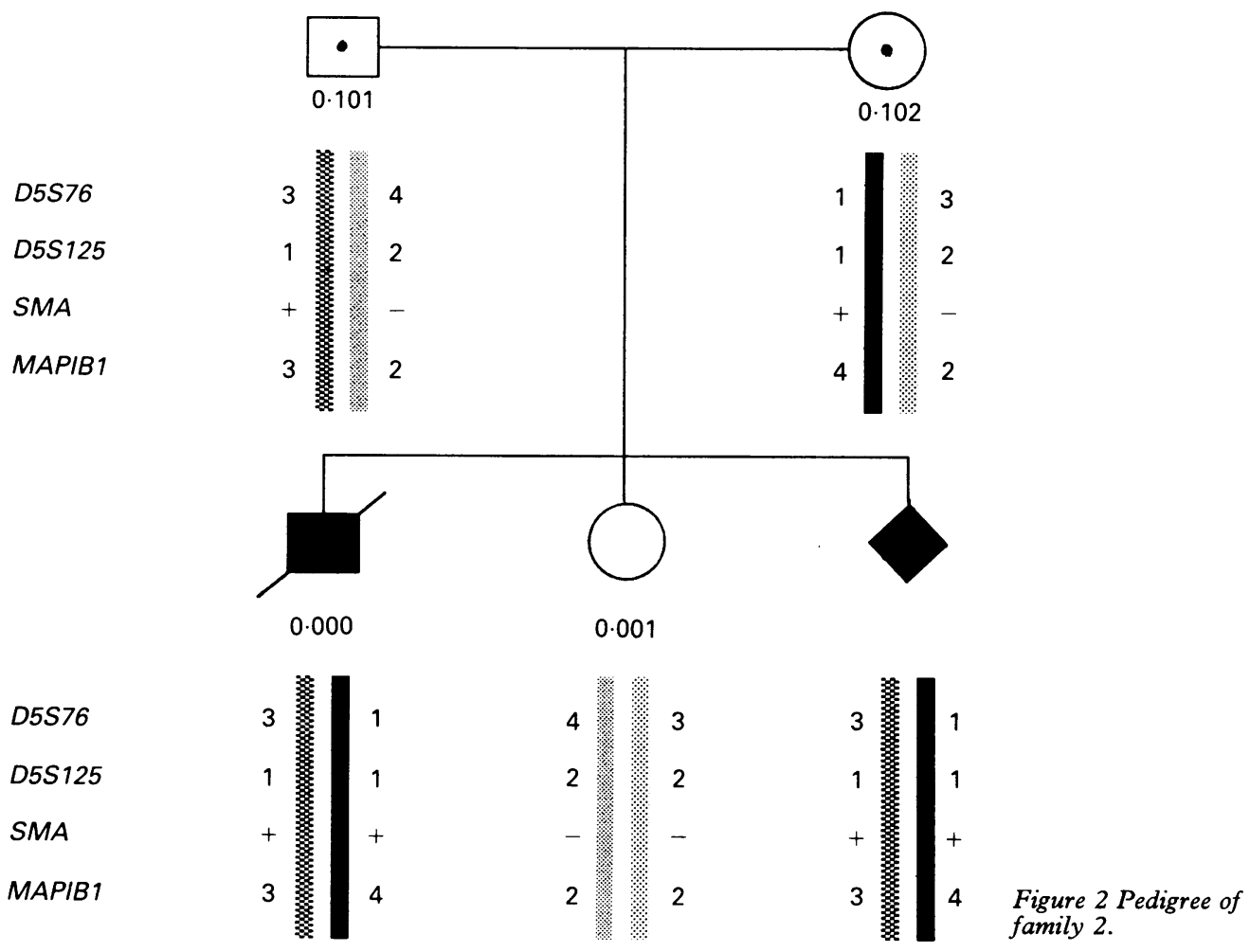

interloci genetic distances of the five $5 \mathrm{q} 13$ microsatellite loci used in this analysis are (\% figures are recombinant fractions) $)^{589}$ :

$$
\begin{aligned}
& D 5 S 76-(4 \%)-D 5 S 125-(1 \%)-S M A- \\
& (1 \%)-M A P 1 B, M A P 2 B-(2.5 \%)-D 5 S 39 .
\end{aligned}
$$

Total informativity was achieved for flanking markers, no marker-marker recombinations were observed, and, unfortunately, in both cases a positive diagnosis of SMA was made (figs 1 and 2).

The diagnosis was communicated to the first family five days after the amniocentesis and the pregnancy was terminated at 17 weeks of gestation. The second family was informed of the diagnosis at 11 weeks' gestation; the pregnancy was terminated at that stage.

We believe with subsequent refinement of this method that the time from amniocentesis to diagnosis, given informativity, will be three days. Moreover, the small amount of amniotic fluid $(100 \mu \mathrm{l})$ required for amplification of microsatellite diagnosis by this methodology may permit amniocentesis at early stages of pregnancy. This approach to prenatal diagnosis is obviously applicable to other monogenic dis- orders which are closely linked to microsatellite repeats.

We wish to thank Dr Linda Surh for suggesting the Chelex based PCR method and Dr Pierre Jacob for his clinical assessments.

1 Daniels RJ, Suthers GK, Morrison KE, et al. Prenatal prediction of spinal muscular atrophy. $\mathcal{F}$ Med Genet 1992; 29:171-4.

2 Melki J, Abdelhak S, Burlet P, et al. Prenatal prediction of Werdnig-Hoffmann disease using linked polymorphic probes. $\mathcal{F}$ Med Genet 1992;29:165-70.

3 Hausmanowa-Petrusewicz I, Fidzianska-Dolot A. In: Gamstorp I, Sarnat HB, eds. Progressive spinal muscular atrophy. New York: Raven Press, 1983.

4 Walsh PS, Metzger DA, Higuchi R. Chelex 100 as a medium for simple extraction of DNA for PCR-based typing from forensic material. BioTechniques 1991;10:506-11.

5 Lien LL, Boyce FM, Kleyn P, et al. Mapping of human microtubule associated protein $1 \mathrm{~B}$ in proximity to the spinal muscular atrophy locus at 5q13.1. Proc Natl Acad Sci USA 1991;88:7873-6.

6 Mankoo BS, Sherrington R, De La Concha A, et al. Two microsatellite polymorphisms at the D5S39 locus. Nucleic Acids Res 1990;19:1963.

7 Sherrington R, Melmer G, Dixon M, et al. Linkage disequilibrium between two highly polymorphic microsatellites. Am f Hum Genet 1991;49:966-71.

8 Sheth P, Abdelhak S, Bachelot MF, et al. Linkage analysis in spinal muscular atrophy, by six closely flanking markers on chromosome 5. Am $\mathcal{f}$ Hum Gene 1991;48:764-8.

9 MacKenzie AE, Roy N, Besner A, Jacob P, Korneluk RG, Surh L. Genetic linkage analysis of Canadian SMA kindreds using flanking microsatellite $5 \mathrm{q} 13$ polymorphisms. Hum Genet (in press). 